Résumés des conférences et travaux

\title{
Histoire de la médecine : maladies, malades, praticiens
}

Joël Coste

\section{OpenEdition}

Journals

Édition électronique

URL : https://journals.openedition.org/ashp/874

DOI : 10.4000/ashp.874

ISSN : 1969-6310

Éditeur

Publications de l'École Pratique des Hautes Études

Édition imprimée

Date de publication : 1 octobre 2009

Pagination : 350-351

ISSN : 0766-0677

\section{Référence électronique}

Joël Coste, "Histoire de la médecine : maladies, malades, praticiens », Annuaire de l'École pratique des hautes études (EPHE), Section des sciences historiques et philologiques [En ligne], 140 | 2009, mis en ligne le 22 octobre 2009, consulté le 06 juillet 2021. URL : http://journals.openedition.org/ashp/874 ; DOI : https://doi.org/10.4000/ashp.874 


\title{
HISTOIRE DE LA MÉDECINE : MALADIES, MALADES, PRATICIENS
}

\author{
Directeur d'études : M. Joël COSTE
}

Programme de l'année 2007-2008 : I. Études d'épidémiologie historique. Blessures, maladies et incapacités des soldats admis à l'Hôtel des Invalides (1670-1791) (suite). - II. Observation et narration médicale à l'époque moderne. Les recueils de conseils, consultations et «observations »(vers 1550-vers 1850) [suite].

\section{I. Études d'épidémiologie historique}

La saisie des données des registres d'admission à l'Hôtel royal des Invalides (portant sur un peu plus de 11300 sujets) n'ayant pu être terminée au cours du printemps 2008, comme cela avait été initialement prévu, la première conférence a été reportée à l'année 2008-2009.

\section{Observation et narration médicale à l'époque moderne}

Toutes les séances de l'année 2007-2008 ont donc été consacrées à la seconde conférence et à la poursuite de l'étude des recueils de consilia et de consultations des médecins français de l'époque moderne. Le recueil manuscrit anonyme et inédit MS5425 de la Bibliothèque inter-universitaire de médecine de Paris, les recueils imprimés de Pierre Chirac (1648-1732) et de Louis-Jean Le Thieullier (17?-1751) ont été successivement considérés. Le MS5425 comprend 109 consultations rédigées entre 1695 et 1706 à Montpellier par plusieurs médecins de cette ville (Barbeyrac, Chirac, Sidobre, Verny) ainsi qu'une consultation rédigée à Paris en 1728 par Chirac et Molin. Le manuscrit, d'une belle écriture appliquée, a pu être attribué à un étudiant de l'entourage de Pierre Chirac - il pourrait s'agir de Jean-Baptiste Silva (1682-1742), élève de Chirac qui a suivi celui-ci à Paris à la fin de la décennie 1700. L'étude de ce manuscrit a permis d'évoquer la formation de Pierre Chirac, auprès de Charles Barbeyrac (1629-1699), et la carrière montpelliéraine du futur médecin du Régent. Les consultations de ce dernier, imprimées dans quatre recueils publiés de manière posthume entre 1742 et 1755 grâce aux soins de Jean-Jacques Bruhier d'Ablaincourt (1685-1756), ont ensuite été analysées. Au nombre de 86 (dont 28 couplées aux mémoires ou demandes d'avis des médecins, des malades ou de leur entourage), elles ont révélé un praticien éclectique, recourant aux remèdes chimiques dans plus de la moitié de ses consultations, mais aussi prudent et réservé dans la rédaction de ses avis. Les dernières séances ont été consacrées aux quatre recueils de Louis-Jean Le Thieullier, docteur régent de la Faculté de Paris et médecin ordinaire de Louis XV. Ces recueils regroupent 150 consultations (dont 147 reproduites à la suite du mémoire initial) rédigées à Paris entre 1735 et 1746 et éditées par l'auteur de son vivant pour l'instruction des jeunes médecins. La personnalité et la pratique clinique de ce médecin peu connu de la Faculté 
de Paris, fortement influencé par le néo-méthodisme d'Hoffmann, ont été précisées. L'étude de ces recueils a également permis d'approfondir nos connaissances sur le déroulement des consultations épistolaires (qui étaient collectives pour certaines d'entre elles) et les « réseaux de relations » mobilisés à cette occasion par les malades et leurs familles, et aussi d'analyser le travail de « ré-élaboration narrative » de la maladie réalisé par les consultants à partir du mémoire reçu (grâce à une analyse croisée des mémoires et des sections narratives des consultations). Enfin, l'étude de l'ensemble (unique) des 147 mémoires adressés à Louis-Jean Le Thieullier, dans lesquels les demandeurs, parfois désemparés, donnaient de nombreux détails sur les maladies et leurs traitements, a permis une approche très directe et très concrète de la réalité pathologique prise en charge par les médecins parisiens au milieu du XVIII ${ }^{e}$ siècle. Grâce à l'exercice du diagnostic rétrospectif - facilité dans ce cas par la richesse des mémoires - nous avons pu constater une nouvelle fois la fréquence, parmi les maladies chroniques faisant l'objet de consultations médicales, des hémiplégies par (probables) accidents vasculaires cérébraux, des suppurations pulmonaires (incluant certainement des tuberculoses), des migraines, des (probables) insuffisances cardiaques, des cirrhoses hépatiques, des lithiases urinaires, des fistules anales, des eczémas, des glaucomes et des cancers de l'utérus. 